Rhode Island College

Digital Commons @ RIC

$5-21-2017$

\title{
Perceived Barriers to Contraceptive Use: An Exploratory Study of Women Living in Rural Haiti
}

Jocelyne de Gouvenain

Rhode Island College

Follow this and additional works at: https://digitalcommons.ric.edu/etd

Part of the Other Nursing Commons, and the Public Health and Community Nursing Commons

\section{Recommended Citation}

de Gouvenain, Jocelyne, "Perceived Barriers to Contraceptive Use: An Exploratory Study of Women Living in Rural Haiti" (2017). Master's Theses, Dissertations, Graduate Research and Major Papers Overview. 194.

https://digitalcommons.ric.edu/etd/194

This Major Paper is brought to you for free and open access by the Master's Theses, Dissertations, Graduate Research and Major Papers at Digital Commons @ RIC. It has been accepted for inclusion in Master's Theses, Dissertations, Graduate Research and Major Papers Overview by an authorized administrator of Digital Commons @ RIC. For more information, please contact digitalcommons@ric.edu. 
PERCEIVED BARRIERS TO CONTRACEPTIVE USE:

AN EXPLORATORY STUDY OF WOMEN LIVING IN RURAL HAITI

by

Jocelyne de Gouvenain

A Major Paper Submitted in Partial Fulfillment

of the Requirements for the Degree of

Master of Science in Nursing

in

The School of Nursing

Rhode Island College

2017 


\begin{abstract}
Maternal health is defined by the World Health Organization (WHO) as the health of women during pregnancy, childbirth, and the postpartum period (WHO, 2016). Maternal health is a very important determinant of Haiti's familial, educational, economic, and environmental development. One key to maternal health is family planning which can empower women to fulfill their familial and community roles. Family planning through contraception offers women the opportunity to gain time between child births by deciding when to get pregnant in relation to their other life obligations. Having fewer children and longer spacing between births provides women and children a better quality of life and an opportunity to be more productive members of their communities. A maternal health assessment for women of childbearing age in rural Beaulieu, Haiti and surrounding villages was conducted to investigate factors leading to unintended pregnancies among women receiving contraceptives at the Erline et Armelle Clinic using the Social Ecological Model as a framework. Implications for advanced practice public health nursing practice, policy, and research were identified and recommendations provided.
\end{abstract}




\section{Acknowledgements}

I would like to acknowledge those who assisted me to complete this important work. First, I would like to thank my husband and best friend, Roland de Gouvenain, who supported me during these years in graduate school. I would like to thank Dr. Joanne Costello, my mentor, first reader, and dedicated advisor. I am grateful to Professor Deborah Kutenplon, my second reader, for her expertise and input related to women's health as my second reader. I am also grateful to Anne Sliney who shared her expertise in global health as my third reader. I would like to thank Lavictoire Nazaire who worked diligently to organize and make arrangements for me to meet with the participants while I was visiting in Haiti. Lastly, I am most grateful to the six anonymous women participants who voluntarily agreed to share their stories with me to improve the health of all women in Haiti and other developing countries. 


\section{Table of Contents}

Background/Statement of the Problem....................................... 1

Literature Review.......................................................... 4

Theoretical Framework.......................................................... 14

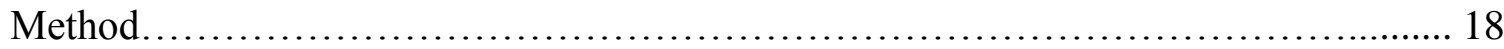

Results................................................................. 23

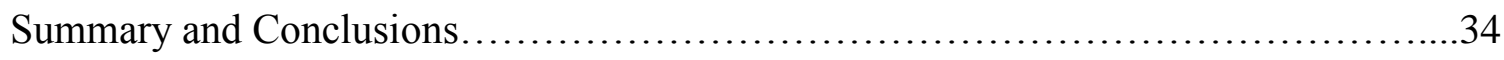

Recommendations and Implications for Advanced Nursing Practice..................40

References............................................................43

Appendices............................................................45 
Perceived Barriers to Contraceptive Use:

An Exploratory Study of Women Living in Rural Haiti

\section{Background/Statement of the Problem}

The movement to promote family planning in developing countries began in the 1960 's in response to large improvements in child survival, which subsequently led to rapid population growth. Promotion of family planning in countries with high birth rates has the potential to reduce poverty and hunger, as well as maternal and childhood deaths. Family planning has greatly contributed to women's empowerment, enhanced universal primary schooling, and long-term environmental sustainability (Cleland, Bernstein, Ezeh, Faundes, Glasier \& Innis, 2006).

A situation closely related to family planning is unintended pregnancy, defined by the Center for Disease Control and prevention (CDC) as a pregnancy that is reported as either unwanted or occurred when no children, or no more children, were desired. Unintended pregnancy is a core concept that is used to better understand the fertility of populations and the unmet need for contraception and family planning. Unintended pregnancy may results from not using contraception or from inconsistent or incorrect use of effective contraceptive methods (CDC, 2015b).

According to the WHO, an estimated 225 million women in developing countries such as Haiti would like to delay or stop childbearing, but these women are not using contraceptive methods to achieve that goal (WHO, 2015b). Every day approximately 830 women die from preventable causes related to pregnancy and child birth and $99 \%$ of these deaths occurred in developing countries. In addition, maternal mortality is higher in women living in rural areas and among poorer communities (WHO, 2016). 
Unintended pregnancy is relevant to public health nursing because of its impact on maternal mortality and on general health and quality of life for families and communities. Globally, in 2013, an estimated 289,000 women died during pregnancy and childbirth, mainly due to lack of, or limited access to, skilled routine and emergency care (UN, 2015). The CDC defines maternal deaths as those deaths that occur during a pregnancy or within 42 days after the end of the pregnancy, during childbirth, or as a result of puerperal complications. The Maternal Mortality Ratio (MMR) is calculated as the number of maternal deaths per 100,000 live births (CDC, 2001).

The project site, the Erline et Armelle Clinic in the rural Haitian village of Beaulieu, is struggling with the problem of unintended pregnancies. Beaulieu is located in southwest Haiti. A map of the area is depicted in Appendix A. This clinic was started in memory of the student researcher's aunt who died during childbirth. The aunt, Erline, died at the age of 35 , leaving behind six young children from birth to 11 years old. She had wanted to stop or space birthing, but she had no resources available to her and had delivered a child every 1-1 $1 / 2$ years until her death.

The clinic was created to provide health care to the women of Beaulieu and surrounding villages with the goal of preventing or reducing maternal mortality and the number of children left orphaned by maternal deaths. Currently, the Erline et Armelle Clinic offers primary care, including birth control services, to women in the community. Most of the women who request contraceptive services at the clinic either receive an injection of Depo-Provera every three months, or birth control pills every month. Although the women are being provided services for contraception, many still experience unintended pregnancies. 
According to a recent WHO report, Haiti has the highest MMR in the Caribbean, with 380 maternal deaths per 100,000 live births. This compares to 100 per 100,000 in the Dominican Republic (DR) which is located on the same island as Haiti and 28 per 100,000 in the United States (WHO, 2015a). Prompted by this startling statistic, the student researcher implemented this study is to assess maternal factors leading to unintended pregnancies in a sample of women of childbearing age living in Beaulieu, Haiti and the surrounding villages. The objective of the project is to better understand women's perceived factors leading to unintended pregnancies, with the goal of improving overall reproductive and maternal health in Beaulieu, Haiti. 


\section{Literature Review}

A literature search of the following databases was conducted: CINAHL, Medline, and Pub Med. In addition, the following web sites were visited: World Health Organization; United Nations; Center for Disease Control \& Prevention; Institute of Medicine; and Google Scholar. The following keywords were used for the search: "unwanted pregnancy developing countries," "unintended pregnancy," "reproductive health Haiti," "women in rural Haiti," "family planning rural Haiti," "birth spacing rural Haiti," "health literacy Haiti," "methods of contraceptives Haiti," and "culture and beliefs Haiti."

\section{Family Planning}

According to the WHO, an estimated 225 million women in developing countries would like to delay or stop childbearing, yet they are not using any method of contraception. Family planning and contraception have multiple advantages, including reinforcing an individual's rights to determine the number and spacing of their children and preventing unwanted pregnancies, unsafe abortions, and deaths of mothers and children. Family planning depends upon access to contraceptive methods and securing the well-being and autonomy of women while supporting the health and development of communities (WHO, 2015b).

A woman's ability to choose when to become pregnant has a direct impact upon her health and well-being. Family planning allows spacing of pregnancies for women who desire more children and prevents pregnancies in very young and older women at increased risk of health problems and death from childbearing. Family planning motivates women to make informed decisions about their reproductive health and is 
therefore beneficial to themselves and to their families, community, and country. It allows women to participate in economic development, obtain an education, contribute to society, and provide a better future for their children and community. (WHO Family Planning and Contraception Fact Sheets, 2015). According to the WHO: Family planning enables people to make informed choices about their sexual and reproductive health. Family planning represents an opportunity for women to pursue additional education and participate in public life, including paid employment in non-family organizations. Additionally, having smaller families allows parents to invest more in each child. Children with fewer siblings tend to stay in school longer than those with many siblings.

(WHO, 2015b)

\section{Family Planning and Poverty in Haiti}

According to the Center for Intelligence Agency (CIA), Haiti is classified as the poorest country in the Western Hemisphere, with $80 \%$ of the population living under the poverty line and $54 \%$ in abject poverty (CIA, 2015). The CIA further states that the overall birth rate in Haiti is 22.31 per 1,000 population and the total fertility rate is 2.69 children born per woman (CIA, 2015). The rates are much higher for rural Haitian women as compared with those living in urban areas.

No other group of the population experienced poverty on a greater scale than rural Haitians, illustrating the link between large family size and deep poverty (CIA, 2015). Furthermore, deep poverty in rural areas is not 
a new phenomenon to rural Haiti. It resulted from years of ineffective governmental policies for population control and family planning services, deforestations, and complete neglect of those living in rural areas (Cleland et al., 2006).

In 2008, Haiti was classified as low-income by the World Bank and the United States Agency for International Development (USAID) because of low food production, a high rate of unemployment, and lack of access to potable water and other basic needs required to sustain comfortable human life. According to the 2008 USAID Haiti country profile:

Haiti is defined as a low-income chronic food deficit country by the World Bank, only able to produce less than half of food needs (43\% in 2008). Fifty-four percent of Haitians live on less than $\$ 1 /$ day. Illiteracy is estimated at $44 \%$ and the unemployment rate in the formal sector is between $70-80 \%$. In addition, $46 \%$ of Haitians do not have sustainable access to potable water and Haiti ranks 154 of 177 countries in the UN's Human Development Index. (USAID, 2008).

Research has demonstrated that women in developing countries have more children as compared to women in developed countries, thereby putting a strain on their limited resources (Cleland et al., 2006). This disparity is related to a lack of education, empowerment and access to contraceptives. When poor women bear many children, the poverty cycle continues because these mothers cannot provide their children with the 
education necessary to become successful members of society. For example, a woman in a rural Haiti a village such as Beaulieu might have 5-7 children. None of these children would attend school because the family cannot afford it, and yet the mother continues to bear more children. This finding is consistent with other developing countries as noted by Cleland et al., (2006):

Elucidation of the link between household poverty and childbearing has proved contentious. Existence of a strong correlation is not in doubt. In 56 developing countries, on average the poorest fifth of women had a fertility rate of six births, compared with 3.2 births in the wealthiest fifth (Cleland et al., 2006).

\section{Family Planning and Maternal/Child Health}

Ezeh, Bongaarts, and Mberu (2012) concluded, "Low income countries do not have the private and public resources to ensure adequate health care, and available healthcare facilities are often unable to serve adequately the ever increasing needs of the population” (Ezeh, Bongaarts, \& Mberu, 2012). Family planning and contraceptives increase the survival rates and health of mothers and children. Spacing time between births allows women to spend more time caring for their infants and dedicate more of the family's resources to them, potentially increasing the survival rates of younger children. The space between birthing also provides women with the time needed for their bodies to recover and to build the strength necessary to care for infants and older siblings. Cleland et al., (2006) reported: 
Family planning also brings large potential health and survival benefits for children, mainly as a result of wider interval between births. Findings of studies in both rich and poor countries show that conceptions taking place within 18 months of a previous livebirth are at greater risk of fetal death, low birthweight, prematurity, and being of small size for gestational age.

(Cleland et al., 2006, p, 1813)

When contraceptives are not accessible, women may find other ways to eliminate unwanted or unintended pregnancies, which can be detrimental to their health, their children and their families. Contraceptives provide women an alternate way to establish balance in their lives and reduce the need for risky behaviors that can result in injury and death. One of these drastic measures is abortion and abortion-related procedures, which can be dangerous if not performed properly. Cleland et al. (2006) reported, "In 2000, about $90 \%$ of global abortion-related and $20 \%$ of obstetric-related mortality and morbidity could have been averted by use of effective contraception by women wishing to postpone or cease further childbearing" (p. 1813).

Access to contraceptives plays a key role in decreasing the MMR by reducing the number of unintended pregnancies and unsafe abortions. Globally, the rate of reproductive-aged women, married or in union, who use contraceptives increased from 55 percent in 1990 to 64 percent in 2015 . Access to healthcare, however, remains the main barrier for women who would like to prevent unintended pregnancy, space, delay, or stop childbearing. 
In rural areas of Haiti, women are more likely to want more children than women living in urban centers because children are needed to work on the farm, help with household chores, and care for elders. Rural women are usually the income earners of the family, often working on farms that produce meager crops due to years of deforestation, land erosion, and lack of irrigation. An additional burden is that these women are required to walk several miles to get the food and water to sustain both their nuclear and extended families, as well as their farm animals. It is, therefore, even more imperative that they remain healthy to fulfill these duties.

\section{The United Nations Support of Maternal, Child Health}

At the beginning of the new millennium, leaders of the United Nations met to develop strategies to eradicate poverty. Their vision was translated into eight Millennium Development Goals (MDG's). The fifth Millennium Development goal targeted improvements in maternal health, with a focus on reducing the MMR by three quarters between 1990 and 2015. According to the 2015 MDG report, maternal survival significantly improved since the adoption of this goal. Worldwide, MMR dropped by 45

percent between 1990 and 2013, from an average of 380 maternal deaths per 100,000 live births to 210. The report documented, however, that while developed nations met and exceeded goals, developing countries did not improve satisfactorily. The report states:

Despite this progress, every day hundreds of women die during pregnancy or from childbirth-related complications. In 2013, most of these deaths were in the developing regions, where the maternal mortality ratio is about 14 times higher than in the developed regions.

(U.N, 2015. p. 39) 
The WHO recommends a minimum of four antenatal visits prior to pregnancy and childbirth to ensure the well-being of mothers and newborn. During the prenatal visits, pregnant women should receive information about their pre-natal care including nutritional advice, signs and symptoms of pregnancy complications, when to seek help, and how to obtain support with their deliveries. Unfortunately, these services are not accessible to many women in developing countries The MDG report states, "During 2014, an average of only 52 percent of pregnant women in the developing regions received the recommended number of antenatal care visits during pregnancy" (U.N, MDG Report 2015. p. 41).

To reduce the MMR in developing countries, the MDG report recommended that every mother be assisted by skilled heath personnel during delivery, and that she receive a minimum of four antenatal visits during the course of a pregnancy and childbirth. Unfortunately, this intervention cannot be fully implemented due to lack of universal healthcare access. The MDG report documented,

Globally, the proportion of deliveries by skilled health personnel increased from 59 percent around 1990 to 71 percent around 2014. Yet this leaves more than one in four babies and their mothers without access to crucial medical care during childbirth. Wide disparities are found among regions in the coverage of skilled attendance at birth.

(U.N, 2015. p. 39)

Considerable discrepancy between urban and rural regions is apparent, as well as between developing and developed countries. The MDG interventions are not countryspecific and fail to consider the fact that rural areas in many developing countries have no 
infrastructures or systems in place to implement these interventions. Lack of existing systems in developing countries place women at a disadvantage. The MDG 2015 Report documents:

Profound inequalities in access to and use of reproductive health services persist within and across regions. In the developing regions, there is a 31 percentage-point gap between urban and rural areas in the coverage of births attended by skilled health personnel, but even this large disparity marks the range of inequalities among regions (U.N, 2015. P. 40).

\section{Healthcare Facility Deliveries in Rural Haiti}

Delivery at a healthcare facility is an important factor in reducing MMR and is reported to be 350 per 100,000 live births in Haiti. In 2010, institutional deliveries were just over $25 \%$ of all Haitian births. A cross-sectional study conducted by Seraphin et al. (2015) at Fond des Blancs and Villa, a rural and isolated region of about 65,000 inhabitants, aimed to identify factors contributing to women's access to medical care during obstetrical emergencies. Study participants were women of childbearing age (1549) who gave birth in the five years preceding the survey $(\mathrm{N}=575)$, (Seraphin. et al., 2015).

The MDG report recommendations to reduce MMR were used as the standard, and outcomes were evaluated by using a "three delays model." The three delays model included: a delay in seeking care for obstetric emergencies, a delay in reaching the nearest health center, and a delay in receiving appropriate care on arrival. In order to 
implement interventions to decrease MMR in low and middle-income countries, factors of preventive delivery care seeking behaviors need to be understood. Seraphin et al., (2015) state that in low income countries like Haiti, antenatal care provided by nongovernmental organization (NGO) offers an educational opportunity to motivate women to choose institutional delivery and thereby reduce maternal and infant mortality:

In Haiti, where low government expenditure and high out of pocket costs prohibit access to healthcare to most of the population, antenatal care clinics are often provided free of charge by non-government organizations (NGOs).

Antenatal care in NGO supported clinics often represents the first contact a woman of childbearing age will have with the healthcare system, and a golden opportunity to motivate her to deliver at a hospital. Uptake of antenatal care and delivery services is however, low. Just over $50 \%$ of pregnant women complete the recommended four antenatal care visits, and only $25 \%$ experience institutional delivery in rural regions of Haiti (Seraphin. et al., 2015).

The study found the prevalence of health facility delivery to be low among women of childbearing age in rural Haiti at $25 \%$ as compared to the Haitian national average of $45 \%$. Older women tended to deliver at home, as compared to younger women. Seraphin et al. (2015) reported, "While over $90 \%$ of the women received antenatal care, a little over $54 \%$ of the women reported to have delivered at home, a trend 
that was more common in older women. Renewed efforts are needed to reach this group" (p. 1406). 


\section{Theoretical Framework}

\section{The Social-Ecological Model}

Socio-ecological models were developed to further the understanding of the dynamic interrelations among various personal and environmental contextual factors. These models were introduced by ecological biologists, psychologists, and sociologists as a reaction to the narrow scope of much of the research being conducted in their fields. Many socio-ecological models were thus developed that viewed phenomena as resulting from reciprocal interactions between variables at multiple individual and environmental levels (Richard, Gauvin, \& Raine, 2011).

Principles of socio-ecological models were used by the Centers for Disease Control and Prevention (CDC) to develop violence prevention programs. Prevention required understanding the factors that influenced violence (Figure. 1). The CDC used a four-level Social-Ecological Model to better understand violence and the effect of potential prevention and intervention strategies. The model focuses on the complex interaction between its four components: individual, relationship, community and societal factors (CDC, 2015a).

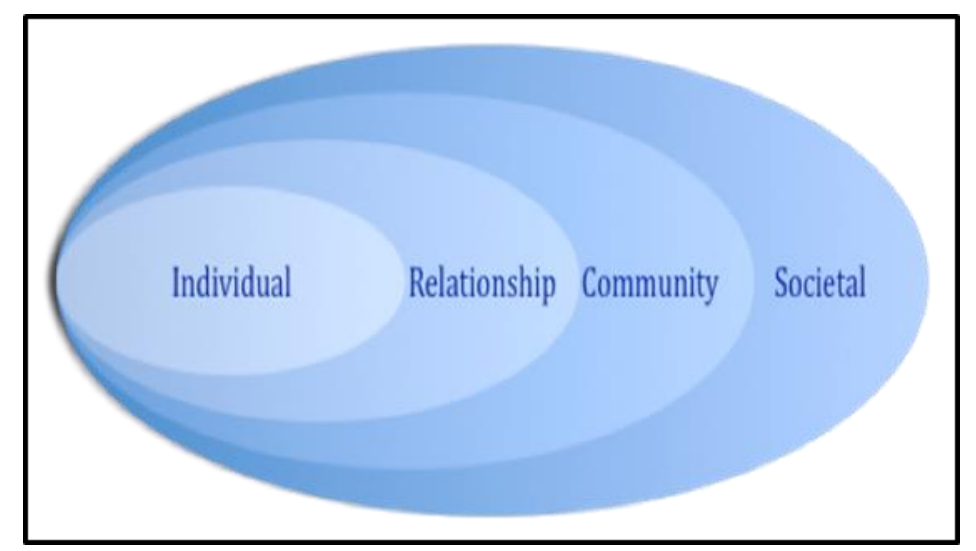

Figure 1. The Social Ecological Model (Image retrieved from:http://www.cdc.gov/violenceprevention/overview/social-ecologicalmodel.html). 
The model developed by the CDC was used as a framework to evaluate the individual as a person who was experiencing or living with a problem or challenge, rather than focusing on the problem itself. The framework focuses on people as integrated within their environments with each part of the contextualized person important to consider in designing effective interventions. The framework emphasizes the importance of evaluating a person's health problems and challenges in relation to his/her environment with the assumption that everything in that environment had an impact on the person's health.

The CDC's Social-Ecological Model provides a framework for understanding why women in rural Haiti experience unintended pregnancies. The model will facilitate exploration of the dynamic and reciprocal relationship of the woman herself, her family, friends, cultural and religious beliefs, community, and societal and governmental context which impacts unintended pregnancy in women in rural Haiti.

\section{Individual level influences}

The first level of the CDC model identifies biological and personal history factors that increased the likelihood that the behavior of interest would occur. Some of the factors considered are age, education, income, and family history. Prevention strategies at this level were designed to promote attitudes and beliefs that positively influenced the behavior. Specific approaches included educational skills training (CDC, 2015a). An example of an application to the women in rural Haiti would be initiating an assessment

of issues on the individual level such as side effects of contraceptive use or health literacy level which might contribute to understanding barriers to pregnancy prevention and inform interventions.

\section{Relationship Level Influences}


The second level of the CDC model examines close relationships that could influence the target behavior. The individuals' closest social contacts such as peers, partners, and family members influence their behavior and contribute to their range of experiences. Prevention strategies at this level include family-focused programs as well as mentoring and peer programs designed to foster the knowledge and skills needed for health (CDC, 2015a). An example of an application to women in rural Haiti would be the husband or in-union partner not wanting the woman to use contraception or the woman and her partner living with "in-laws" and not wanting them to know about contraceptive use.

\section{Community Level Influences}

The third level of the Social Ecological Model explores community institutions and environmental context such as schools, churches, workplaces, and homes/neighborhoods in which social relationships occur to identify the characteristics of these settings that would be associated with the behavior of interest. Prevention strategies at this level are typically designed to impact the social and physical environment. For example, interventions aimed at reducing social isolation and improving economic and housing opportunities in neighborhoods are considered community level interventions (CDC, 2015a). In rural Haiti where most of the population is Roman Catholic, religious teachings which forbid the use of artificial contraception could result in women not choosing to limit the size of their families. Also, natural disasters such as Hurricane Matthew which destroyed much of the housing in Beaulieu in October of 2016 might impact upon women's privacy in using contraception if they are not living in their own homes. 


\section{Social Level Influences}

The fourth level of the CDC model addresses broad societal factors which create a climate in which the target behavior was encouraged or inhibited. These factors included social and cultural norms that supported the behaviors. Other macroscopic societal factors included the health, economic, educational, and social policies that contributed to continuing economic or social inequalities between groups in society (CDC, 2015a). Applications at this level might include Haitian governmental and non-governmental organizations being involved in policy changes that support family planning or reduce poverty. For example, in rural Haiti, no health insurance exists and women are required to pay for contraceptives. In addition, governmental policies which cause "stock outs" or the inability to obtain contraceptives nationally are considered to occur at the societal level. In order to understand unintended pregnancy at the individual level, all levels of the Social-Ecological Model need to be considered and integrated into strategies for maternal child health promotion. 


\section{Purpose and Design}

\section{Method}

The purpose of this project was to interview a sample of rural Haitian women of childbearing age regarding barriers to contraceptive use and factors leading to unintended pregnancies with the goal of improving overall reproductive and maternal health. This study utilized an exploratory qualitative design involving semi-structured, in-depth interviews of women living in Beaulieu and surrounding villages who experienced unintended pregnancies.

\section{Sample}

The targeted population sample were women who were provided family planning services at the Erline et Armelle Clinic in Beaulieu, Haiti. The sample size was six women who experienced unintended pregnancy while receiving contraceptives. Inclusion criteria were being female between the ages of 18 and 55 and having had at least one unintended pregnancy while being prescribed contraceptives from the Beaulieu Clinic. Exclusion criteria included women who: had never experienced unintended pregnancy; were post-menopausal; only had planned pregnancies; had never been prescribed contraceptives at the clinic site; were less than 18 years of age or over 55; and/or declined to participate. The six participants were all born and lived their entire lives in Beaulieu and the surrounding villages in Haiti. All received health services including contraception at the Beaulieu Clinic.

\section{Site}

The study was conducted at the Erline et Armelle's Clinic in rural Beaulieu, Haiti. A letter of agreement was provided by the Haitian Humanitarian Network, the 
organization which supports and provides administrative services for the clinic, to conduct the study at the clinic (Appendix B). The clinic was founded in 2003 to provide health care and health promoting activities to the people of Beaulieu and surrounding villages. Currently, the clinic is staffed by one full-time nurse and one part-time physician. It contains a reception area, two examination rooms, an administrative office, a storage area, and a pharmacy. The clinic provides primary care and health promotion interventions to an average of 250 patients per month or approximately 3000 per year. A photo of the clinic is presented as Appendix C.

\section{Procedures}

The project proposal received approval by the Rhode Island College Institutional Review Board (IRB). Care was taken that the potential conflict of interest existing since the student researcher was the founder of the clinic and currently serves on the Board of Directors would not impact the integrity of the study. The researcher recused herself from the vote regarding participation and the voting was private and results known only to the Chair of the Board of Directors.

A document, Script for Clinic Nurse to Invite Participants, was developed by the researcher and used by the clinic nurse to invite women who met the study criteria to participate in their native Haitian Creole. The script is available as Appendix D (English) and E (Haitian Creole). Women were invited to participate in the study and were told that they could choose not to participate. In addition, they were informed that declining to participate would have no effect on their or their family members' treatment or services at the clinic. Participants were told that their participation was voluntary and that they had the right to withdrawal from the study at any time. 
Informed consent was obtained to participate in the interview and to audiotape the interview using an informational letter in Haitian Creole which was provided and read to each potential participant prior to interviews by the researcher. The purpose and process of the study was explained in detail verbally using the informational letter. The informational letter was written at the participants' literacy level to assure understanding of its content and using words familiar to villagers. The informational letters in English (Appendix F) and Haitian Creole (Appendix G) are available as Appendices.

The identity of each participant was protected. All information collected was completely anonymous with no identifying data. Data collected was not included in the clinic medical record. Interviews were tape recorded and transcriptions kept anonymous through use of a unique identifier code. The tapes and transcripts are stored in a locked cabinet which is in a private area and not accessible. The six women agreed to participate in an interview and be audio recorded, and audio recording was done only after receiving the permission from each participant. A small gift of a hand towel and bar soap was given to the women as a token of gratitude for their participation.

The student researcher, a native Haitian fluent in Haitian Creole, developed an interview guide with open-ended qualitative questions. The interview guide was based on the student researcher's knowledge of the Haitian community and a comprehensive literature review. This guide was written in English and then translated into Haitian Creole. It is available as Appendix H (English) and I (Haitian Creole).

The student researcher conducted all interviews individually in Haitian Creole. The setting was a private examination room where the women usually received health 
care and contraception treatment. Data collection involved in-depth interviews of approximately 30-60 minutes which were audiotaped.

An exploratory qualitative design was used to elicit women's perceptions of barriers to contraceptive use and factors contributing to unintended pregnancies. Semistructured and in-depth methods provided the interviewer with the flexibility to modify questions and adapt the interview to individual responses. Data collected through interviews included demographical information such as age, marital status, educational level, occupation, and distance/time to travel to the clinic. In addition, women were asked about maternal family planning issues including: number of pregnancies, age at pregnancies, number of live births and children deceased, type and duration of contraceptive use, pregnancies during contraceptive use, and breast feeding status. Using information gained from the literature review, women were interviewed about their knowledge of and reasons for using contraceptives, side effects experienced, potential barriers such as partner/spousal lack of support, religious and cultural impact upon contraceptive use, housing insecurity, accessibility of contraceptives, and other potential barriers. The interview questions were developed to be appropriate to the women's cultural background and literacy level.

Audiotaped interviews were transcribed into Haitian Creole then translated into English for analysis. An excel spread sheet using a unique identifier was created to organize data into categories to facilitate analysis. Qualitative data was reviewed and analyzed to identify themes related to knowledge of contraceptives and barriers to contraceptive use and adherence. Themes were categorized using concepts from the 
Social-Ecological Model theoretical framework. A second reader analyzed the data to provide confirmation of category assignment and interpretation of results. 


\section{Results}

\section{Individual Level Factors}

Factors potentially impacting prevention of unintended pregnancy on the individual level were analyzed. This included demographics, type and duration of contraceptive use, reasons for contraceptive use, knowledge of contraceptive use, and side effects of contraception.

Demographics. The age of the six participants ranged from 23-42 years old with a mean age of 31 years old. Participants' age at their first pregnancy ranged from 16-20 years old with a mean of 18 years old. The number of pregnancies ranged from 3-9 with a mean of 4.17. The six women who participated had live births ranging from 2-7 with an average of 3.8 live births per woman. The ages of the participants' children ranged from 2-23 years old.

Five of the six participants reported attending primary school, and one chose not to answer the question during the interview. School attendance for participants ranged from 3-9 years, and averaged five years of education for the women participating. The ability to read and write was variable. Three of the six participants reported being able to read and write. One reported that she could read, but not write. Another reported that she "could not hardly read or write." Another reported that she could not read or write at all.

Type and duration of contraceptive use. All six participants reported receiving contraceptive injections of medroxyprogesterone acetate (Depo-Provera) every three months as their contraceptive method. The six participants stated that they had been using contraception for three to seven years with an average of five years of duration of use. One woman reported that after being on the Depo-Provera injection for several years, she 
subsequently used Confiance oral contraceptive because she was unable to obtain the injection at the Beaulieu Clinic.

Reasons for contraceptive use. When asked about reasons for using contraception, the participants responded that it was beneficial generally, was beneficial for their own health and well-being, and beneficial to their family to have less children. One participant, a 24 year old married woman who had three children, stated generally, " $I$ think it is better to have less children." A 34 year old woman who was living "in union" and had three children primarily considered her own well-being in the decision, stating "It is better for me." A 31 year old who had two children and was living "in union" stated, "I think it has helped me to have less kids because it is not a big deal to handle a small family." Another 23 year old woman living "in union” who had three children stated, "I didn't want to be pregnant. Raising and educating many children is not easy." A 34 year old participant who lives with her partner "in union" and had four children stated, "I take the family planning to help myself, to help my family not to have too many children." A 42 year old married woman who had nine pregnancies and seven children believed that preventing pregnancies would impact the health of her children. She stated, "It would help me not to have too many children and provide my family a (sic) better health."

Knowledge of contraceptives. The women were asked to describe the knowledge they had of contraceptives and how the contraceptive they used to prevent pregnancy worked. One participant was not able to express any knowledge of contraceptives and how it worked. Two participants expressed the relationship between contraception and pregnancy. They articulated simply that not taking it resulted in pregnancy. One stated, 
"It works at all because once you leave it you will be pregnant. But if you stay on it you won't."

Three other women expressed their knowledge which was limited to the pragmatic aspect of the process of the required interval of injections. One stated, "I think the family planning can help you not to be pregnant if you follow carefully the method. Every three months, just go for your injection on time." A second woman expressed knowledge that maintenance of injections at three month intervals resulted in pregnancy prevention. She stated, "A women has to be on time for her appointment about family planning at the clinic. If woman does so exactly, it will prevent her from becoming pregnant." And another woman said, "Every three months I come to take the injection. I don't have any problem if I go for my appointment." None verbalized any specific understanding of how the injections that they are receiving every three months prevented them from becoming pregnant.

Side Effects of Contraception. All six of the women stated that the complications experienced from taking the contraception were tolerable and that the benefits outweighed the problems experienced. Some minor complications which the women attributed to the contraception were reported. Four women reported not having their periods while taking contraception. One stated, "I only don't see my period, but I don't worry about it." Another stated, "Nothing else except I don't see my period." One woman reported increased menstrual flow with the medications. She stated, "I bled too much. I gave too much blood." One women reported experiencing some headache and dizziness. Another woman reported multiple side effects including, dizziness, blurred vision, amenorrhea, and abdominal swelling. She stated, "I feel dizzy, sometimes my eyes 
were blurry. I could not have my period. My belly used to be swollen." None reported that they wanted to discontinue contraceptives because of the reported side effects.

\section{Interpersonal Level Factors}

Factors potentially impacting prevention of unintended pregnancy on the interpersonal level were analyzed. These factors include the impact of the partner/husband's perspective on contraceptive use and the impact of living with extended family members on contraceptive adherence.

Partner or husband impact on contraception use. Women were asked about their marital status. Four of the 6 participants reported living in-union or monogamous partner status relationships. Two of the 6 participants reported being married. Six of the six participants reported that their sexual partners were aware that they were receiving contraceptives to prevent pregnancy and were supportive of this decision. No participant reported the need to hide medication from their partners.

Housing and extended family impact on contraceptive use. All six participants owned their own houses in Beaulieu and the surrounding villages prior to a natural disaster occurring in the fall of 2016. In October 2016, all six of the participants' homes were destroyed by Hurricane Matthew which directly struck southwest Haiti. Three of participants reported still not being able to live in their homes three months following the hurricane, and living with relatives in nearby villages. Four reported living under a tent covered with a tarpaulin cover. One participant stated, "It is actually a tough situation for me. I build a small tent with a tarp on top so my children, and I can stay in it." Another participant stated, "We build a tent but it is leaking. We are living a tent made with tarp on top." A third woman reported, "I got a tarp as a gift from someone and I used it as the 
roof for my tent." Six of the six participants reported that no negative feedback or impairment of the ability to use contraceptives from extended family members. All participants reported that their current living situation did not impact upon their ability to use their choice of contraception.

\section{Community Level Impact}

The population living in Haiti, including Beaulieu, are largely Roman Catholic. The Roman Catholic religion does not support artificial contraception which could potentially impact family planning choices of the women living in this area. The impact of religion potentially impacting prevention of unintended pregnancy on the community level was analyzed

Religious influences on contraception use. The women were asked about the influence of religion on their contraception decisions. Five of the six woman responded that they considered their religion in making contraceptive decisions, and one stated that she did not. Four women who stated that religion was a consideration in their decision decided that in spite of their religion not allowing artificial contraception, that it was the right choice for them and their families. None expressed having concerns about their choice. Two specifically stated that they did not want the church to be aware of their contraceptive use. One stated, “The church doesn't agree with that, but the people don't know if I am on family planning medication." The other stated, "Yes, because if you are part of the church, you are not allowed to do it. They don't know about me." One who attended a church in the surrounding village stated that her church supports contraception for women. She stated, "My church agrees on that."

\section{Societal Level Influences}


Poverty as a barrier to contraceptive use. Participants were asked about how they traveled to the clinic from their homes and how much time and money was used for the travel. The cost in terms of time and money are potential barriers to contraceptive use since time which could have been spent earning money would be devoted to travel and visit time. In addition, the cost of transportation and the cost of the visit relative to the small amount of income could pose a critical burden on women in accessing contraception.

One of the six participants reported that she lived close to the clinic and walked without incurring travel expense. Two of the six participants reported walking long distances to the clinic. One of these reported walking for one hour each way to get to the clinic, and one participant reported walking for two hours each way. Three others reported taking motorcycle taxis to get to the clinic. They reported that the expense incurred was approximately 63 gourdes round trip, equivalent to 92 cents in US currency. These expenses were reported to be barriers to these participants because relative to their incomes and current economic situations, the travel was perceived as a significant expense.

In addition to the medication not being available to women who wanted to access it, lack of financial resources was identified by one participant who is a married 24 year old with 3 children. A registration fee which was charged for each contraception visit was stated to be more than she could afford to pay by this participant. She stated, "I used to take the injection every three months. I got pregnant because I ran out of money." She later stated, "I don't mind taking the injection, but I am moneyless." 
Accessibility of medication as a barrier to contraceptive use. Accessibility of contraceptives was reported to be a major barrier for the all six of the women, not just at the Beaulieu clinic, but also at nearby clinics in Aux Cayes and Port-Salut. The clinic not having contraceptive medications available when women arrived for routine injections was a critical issue for the participants interviewed. The women reported attempting to get their injections and not being able to obtain them on multiple occasions. One married 42 year old woman who had her first child at nineteen and was pregnant again at the time of the interview with her eighth living child (one deceased) reported that she became pregnant because of not getting the injection when it was not available at the clinic. A 23 year old single mother of three stated, "I couldn't find the family planning. I even went to Port-Salut in order to get it but in vain. Finally, I was pregnant.... I got pregnant because I couldn't find the medication." A participant who was a single 34 year old who has four children and was pregnant with her fifth states, "I came here to the clinic to get the family planning medication, and I could not find it. I even went to Aux Cayes, same thing. In the meantime, I was pregnant." A single 36 year old pregnant woman with six children was also unable to get the injection of Depo-Provera when she went for her appointment to the clinic. She stated, "I could not find it. I have gone to Port-Salut, same thing happened. Finally, I became pregnant." She states, "It would be great to have the medication from the clinic easily." One single 38 year old with four children who is currently pregnant with her fifth reported that it was a big challenge for her to obtain the medication. She walked for one hour to the clinic each time, but no contraceptive was available. She states, "I went to the clinic for the medication many times. I did not find it. That is why I became pregnant." When asked why she became pregnant while on the 
contraceptives, a second single 31 year old mother of two who is pregnant with her third stated, "I went to take my medicine at the clinic, but at that time, I didn't find it. After, I became pregnant." She requested that the doctor and nurses at the clinic "notify the person in charge when they are about to run out of the medication so he or she can provide the clinic before it is too late so they will be able to handle it better."

\section{Limitations}

This pilot study was designed to establish the foundation for improving the quality of women's health care in Beaulieu and the surrounding villages, but has some limitations. The limitations of this study include: the small sample size; the culture and literacy level of the participants; the post disaster environment; the exclusion of women younger than 18 years of age and older than 55 years old who experienced unintended pregnancy; and the researcher's status as a former member of the community and current member of the Haitian Humanitarian Network Board of Directors.

For this pilot study, six participants were interviewed to assess their perception of unintended pregnancy. This sample represented a very small percentage of women experiencing unintended pregnancies in rural Beaulieu and surrounding villages. This sample size was chosen because of limited resources and the limited time the student researcher had to complete interviews while in Haiti. The sample size is also small because of the considerable barriers the women experience coming to the clinic from their remote locations.

The student researcher conducted the interviews during a short visit to Haiti in January of 2017. The recruitment of participants, obtaining consent, and completion of 
the interview process was time consuming and not possible to accomplish on a large scale during the time the researcher was "in country."

The small sample was also related to the distance that women traveled to participate. Five of the six women either walked one to two hours each way for the interview or paid for transportation at significant cost relative to their incomes. This reduced the number of women who could participate during the time constraints of the study.

The culture and literacy level of the participants may have impacted the results of this study. Culturally, many Haitian women may feel uncomfortable talking about the issue of unintended pregnancy and may not completely reveal the information sought because of this discomfort and shame. In addition, the perspective of answering questions in the Western and linear method is not shared by Haitians. Instead, culture may impact the participant response and cause the participants to not answer questions in sequence and to weave a tapestry in telling their story rather than a direct response. This complicates the process and leads to tangential information. Often, participants may respond, but do not answer the specific questions which were asked. In addition to not answering directly, most women did not answer questions in the order they were asked which made data retrieval and analysis complex and challenging.

Literacy level impacted the data collection as well since written surveys could not be completed by respondents in this community which impacted the method of the study. If literacy levels were higher, using a survey method would allow for greater privacy for those responding and for a larger sample of participants. Tailoring the data collection to this population, the student researcher provided individual verbal interviews. Also, every 
question was asked in Haitian Creole and read them to each participant because very few could read. Also, due to low literacy levels, the interview process was limited to interview questions developed using simple phrases that could be easily understood by participants. All questions were designed to be appropriate to the literacy level of the women which did not allow for complex questions that might have provided most multifaceted information to the researcher about the etiology of the issue.

An additional limitation was an environmental disaster which may have impacted the results of this study. A category 4 hurricane, Hurricane Matthew, hit Haiti's southern peninsula on October 4, 2016, three months prior to the study. Most houses in Beaulieu and the surrounding villages were destroyed. The people of the area, including the participants, were still in shock at the time of the interview and trying to cope with the aftermath of the disaster. This may have impacted how people were able to process and answer interview questions. The barriers resulting from the hurricane such as lack of accessible roads, communication delays, and resource damage may have also impacted the availability of contraceptive supplies to remote rural clinics.

When participants were asked if they would like to talk to someone about their current hardship exacerbated by hurricane Matthew, 5 of the 6 did not answer that question. One woman wished to talk to someone since her baby was born only a week before the hurricane, and she was particularly sad for her baby living under such stressful circumstances. She was provided additional time to talk and was referred to the clinic nurse who provided her with emotional support.

Women who were less than 18 years old or greater than 55 years old were excluded from the pilot study although they might have experienced unintended 
pregnancy. This may have an impact on the results of the study, particularly for those under 18 , since many women in Haiti give birth prior to age 18. Although the interviews provided valuable information which will drive quality improvement for the clinic, having feedback from a large number of women and from wider age range who received family planning services from the Beaulieu Clinic would improve the understanding of this issue. Further study should be funded and involve a larger pool of participants, including women who are under 18 years old and over 55 years old. This would increase the study reliability and provide a broader understanding of unintended pregnancy among rural women in Haiti.

Lastly, a potential limitation is that the student researcher was a member of the community of Beaulieu. She was born in Beaulieu and currently has relatives living there. She is also a founder and member of the Board of Directors of the Haitian Humanitarian Network which provides funding and oversight for the Erline et Armelle Clinic. While protection from negative consequences for the women and her family and confidentiality were assured verbally in the informational letter, some participants may have wanted to withhold information which might be embarrassing to themselves and families. Although they were assured that their responses would not impact their or their families' health care at the clinic, some women may have not fully disclosed information which they did not think the researcher would want to know such as negative information about the clinic. 


\section{Summary and Conclusions}

\section{Summary}

An exploratory pilot study was implemented to assess barriers in preventing unintended pregnancies in a sample of women of childbearing age living in rural Beaulieu, Haiti and the surrounding villages. The objective of the project was to better understand the factors leading to unintended pregnancies with the goal of improving overall maternal and child health in this area of Haiti. A qualitative design was used with semi-structured, in-depth interviews of six participants. The sample chosen was women between the ages of 18 and 55 who obtained contraceptives at the Erline et Armelle Clinic in Beaulieu, Haiti and experienced pregnancy while being prescribed contraceptives by the clinic.

Following Rhode Island College Institutional Review Board approval, the interviews were conducted at the Erline et Armelle Clinic in a private location in the clinic. The women were invited to be part of the study at their routine appointments and given the dates and times of the research to participate. They were assured that nonparticipation would not impact their or their family's care. The interviews were conducted by the student researcher who was born in Beaulieu, Haiti, speaks Haitian Creole, and is on the Board of Directors of the Haitian Humanitarian Network (HHN) which provides funding and oversight to the clinic. HHN approved the study and welcomed assistance in accessing information on this significant health problem since the clinic did not have the funding or personnel resources to evaluate the issue.

An informational letter which was in Haitian Creole and developed at the literacy level of the participants using familiar language and culturally appropriate content was 
provided to the participants to obtain informed consent. The letter was read to the women to assure their understanding, and they were asked if they would like to proceed with the interview. They were told that they could stop the interview at any time and did not have to answer any questions that they did not want to answer.

The researcher used an interview guide with open ended questions to guide the interview. Interviews lasted 30-60 minutes and were audiotaped in the participants' native Haitian Creole and translated into English. Questions included demographic information such as age, number of children, marital status, and educational level. They were also asked questions about the type and duration of contraceptive use; side effects of contraceptive use; knowledge of contraceptives and barriers to contraceptive use; and accessibility of contraceptives.

The age of the six women who participated ranged from 23-42 years old with a mean age of 31 years old. These women averaged 4.17 pregnancies per woman and ranged from 3-9 pregnancies. The participants' children's ages ranged from 2-23 years old. Public education is not widely available in Haiti. The five participants who answered the question had an average of five years of education. The range for these five was 3-9 years. Three of the six participants reported that they could read and write. The level of education was variable, but literacy skills were significantly limited for all of them. All of the women were born in Beaulieu and the surrounding villages and had not traveled far from this area.

Four of the six participants were living "in union" or monogamous partner relationships, not an uncommon situation for many families in this rural area. The remaining two reported being married. A potential barrier to contraceptive use, the 
partner or husband not wanting to prevent pregnancy, did not prove to be the case for the participants interviewed. The women reported that their partners/husbands were aware that they used contraception to prevent pregnancy and were supportive of this decision. No participant reported the need to hide contraceptive medication from their partners.

Reasons for using contraception were that it was beneficial generally, was beneficial for their own health and quality of life, and that it was beneficial for their children and family. Participants did not verbalize any depth of knowledge of the process by which pregnancy is prevented through contraceptive use. None of the women could verbalize any specific understanding of how the injections that they received every three months prevented them from becoming pregnant. Their knowledge was limited to knowing that taking the injection resulted in not becoming pregnant and not taking it resulted in pregnancy and to knowing that the interval needed to be 3 months between injections for it to work. Side effects of contraceptive medications reported were minimal and did not impact upon women's taking them as prescribed. All of the women stated that the complications were tolerable and that the benefits outweighed the problems experienced. None reported that they did not want to continue contraceptive treatment due to side effects.

Five of the six participants reported that they considered their religion in deciding whether to use contraceptives. Four of the five women who considered their religion in the decision to take contraceptives decided that in spite of their religion not allowing artificial contraception, they decided that it was right for themselves and their families. None expressed concerns about this choice. 
Housing can be an issue in Haiti at any time, but at the time of the pilot study, Beaulieu and the surrounding villages were less than three months following the direct impact of Hurricane Matthew, a Category 4 hurricane with 146 miles per hour winds. All of the women who participated in the study had owned their own their homes in Beaulieu prior to the hurricane, but all had had their homes destroyed. Four of the six women were living with their children under tents with tarpaulin covers. Examples of a homes in which Beaulieu villagers were currently living is seen in Appendix I. Although the women verbalized experiencing stress from the trauma of the disaster, all six of the participants, including the one living with in-laws, responded that their current living situation had not impacted upon their ability to use their choice of contraceptive.

The mountainous environment and tropical climate present challenges to the women who walk long distances. The 63 gourdes round trip average cost for the three participants taking taxis to get to the clinic (\$0.92 US) represented a large sum of money relative to their income. All the women reported coming to the clinic for their contraception every three months for their injection without regard for the challenges of travel. The registration fee for each quarterly injection visit was reported to present a significant burden and barrier to contraceptive use for one of the six women. The women paid 63 gourdes, the equivalent of $\$ 0.92$, for registration and the injection. All who come to the clinic pay 10 gourdes for registration, the equivalent of $\$ 0.14$. The injection was $\$ 0.53$ in addition to the registration cost, which was perceived to be excessive and burdensome by one of the six participants.

The most significant barrier to contraceptive use and contributor to unintended pregnancy for the women participating was lack of contraceptive product availability at 
the Beaulieu clinic. All six of the women reported that lack of accessibility to the contraception was a serious issue for them. Five of the participants stated that they came for their appointments on more than one occasion to Beaulieu and were not able to get their injections. This was true not just at the Beaulieu clinic, but also at nearby clinics in Aux Cayes and Port-Salut. Five of the six women reported becoming pregnant due to the clinic not having the Depo-Provera injection at the time it was due. Regulatory and taxation issues because of Haitian governmental policies as well as post Hurricane Matthew transportation and funding challenges are the most likely etiology of this "stockout" issue.

\section{Conclusions}

This qualitative pilot study provides important information about underlying issues which may impact unintended pregnancy in women in developing nations who are living in poverty. For this small sample of women living in a rural area of a developing country and have recently experienced a serious natural disaster, barriers at the individual, relationship, and community level do not appear to be major barriers to contraceptive use. One individual level issue that perhaps could be improved is the lack of knowledge of how the contraceptives work at the individual level. This may have contributed to women not using alternative methods such as oral contraception or barrier protection, although these methods may not have been available as well. Also, psychosocial support for women may improve self-advocacy and knowledge levels which may lead to improved health outcomes.

The major barrier to unintended pregnancy prevention for women participating in this study are at the societal level. Access to long acting reversible contraception (LARC) 
which prevents pregnancy for longer periods of time than every three months including intrauterine devices (IUD's) and implants would provide buffers for women when national shortages or environmental disasters which may impact on access occur. In addition, garnering governmental and non-governmental organization (NGO) resources to provide financial support so that women living in poverty can have access to contraception without charge would facilitate maternal and child health for all. 


\section{Recommendations and Implications for Advanced Nursing}

\section{Recommendations}

Recommendations which have been developed based upon this pilot research study of women in rural Haiti are:

1. Seek funding and access to alternative methods of long acting reversible contraceptives such as intrauterine devices and subdermal implants

2. Provide education and support for women and improved ongoing program evaluation through initiation of a maternal health education and support group

3. Engage men in family planning to strengthen family units and share responsibility for contraception

4. Establish policies which provide contraception to women without regard for their ability to pay

5. Conduct large scale research to further assess barriers to pregnancy prevention in women in developing countries

6. Conduct research which evaluates strategies to increase access of LARC to women in developing countries

\section{Implications for Advanced Nursing Practice, Policy, and Research}

This exploratory pilot study of the perception of six women about the factors

impacting unintended pregnancy has implications for advanced public health nursing practice, policy, and research. This public health nursing pilot study used a qualitative method to provide a broader understanding of why the health outcome of unintended pregnancy occurs. Public health nursing seeks to answer why negative health behaviors, diseases, or health conditions occur by investigating root causes, observing people's 
interaction with their environment, and allowing people who live the experience to tell their story. Using the Social-Ecological Theory as a framework, individual, interpersonal, community, and societal factors were used to understand how to impact the lives of populations, particularly women attempting to prevent with unintended pregnancy living in a poor rural community in a developing nation.

Implications for practice include the need for governmental and non-governmental organizations such as the Beaulieu clinic to expand their interventions and provide alternate methods of making contraception more available to women. Long acting reversible contraceptives including intrauterine devices and implants which provide years of safe pregnancy prevention would be particularly important in this and other areas where supplies of shorter acting contraceptives might be not be dependable due to political or environmental issues. In addition, having "backup" oral daily contraceptives and barrier methods available in sufficient quantity for when the injection or LARC are unavailable would provide a second line of defense for women wanting to prevent unintended pregnancy.

Establishing a support group for women to provide education and psychosocial support would also improve their ability to promote their own and their children's health. Encouraging family planning services to be viewed not only as a way to control one's fertility, but also as a way for women to increase their economic status and selfdependence would be an important goal for the clinic in educating women about contraceptives. This would allow personal choice for women rather than dependence on their partners or husbands for survival. Collaborating with women to improve their knowledge of how contraceptives prevent pregnancy and options for pregnancy 
prevention would allow women to plan and implement alternative strategies if their contraceptive of choice is not available. Nurturing mutual support among women would strengthen the community and improve psychosocial as well as physical health.

Policy implications to address family planning should involve providing economic incentives on a global basis for developing countries to remove barriers to access to contraceptives by women. The health of women and their children must be more visibly connected by world leaders to the economic health of nations. Investment in women and families represents ethical choices of societies which will reap significant benefits for the whole nation. The establishment of policies which provide alternate methods of funding so that women are able to access contraception without regard for their ability to pay would improve the lives of countless women and children worldwide. These policies may also aid in shifting social norms and gender roles surrounding family planning and increase women choices to utilize contraceptives.

Further research is necessary to better understand the underlying causes of unintended pregnancy in women living in poverty in developing countries and to establish the most effective strategies to provide access to LARC to all women regardless of their ability to pay. Both qualitative and quantitative research will allow better understanding of this complex issue with individual, interpersonal, community, and societal implications. Future qualitative and quantitative research can be used to assist in the development of appropriate assessment and evaluation tools. Research findings will guide the implementation of policies to address women' reproductive and health care needs with the goal of strengthening the health and quality of life of families. 


\section{References}

CDC. (2001). Maternal Mortality. Atlanta, GA: U.S. Department of Health \& Human Services.

CDC. (2008). Data Collection Methods for Program Evaluation: Questionnaires. Evaluation Briefs.

CDC. (2015a). The Social-Ecological Model: A Framework for Prevention. Retrieved 5/30/16, 2016

CDC. (2015b). Unintended Pregnancy Prevention. Atlanta, GA, US: Center for Disease Control and Prevention.

CIA. (2015). USAID HAITI Country Profile. United States Government.

Cleland, John, Bernstein, Stan, Ezeh, Alex, Faundes, Anibal, Glasier, Anna, \& Innis, Jolene. (2006). Family planning: the unfinished agenda. The Lancet, 368(9549), 1810-1827. doi: 10.1016/S0140-6736(06)69480-4

Ezeh, Alex C., Bongaarts, John, \& Mberu, Blessing. (2012). Global population trends and policy options. The Lancet, 380 (9837), 142-148. doi: 10.1016/S0140-6736(12)60696-5

Lubetkin., E. I, Zabor., E. C, Isaac., K, Brennessel., D, Kemeny., M, \& Hay., J. L. (2015). Health literacy, information seeking, and trust in information in Haitians. Am J Health Behav, 39(3), 441-450. doi: http://dx.doi.org/10.5993/AJHB.39.3.16

Richard, L., Gauvin, L., \& Raine, K. (2011). Ecological models revisited: Their uses and evolution in health promotion over two decades, Annual Review of Public Health, Vol. 32:307326 
Seraphin., M. N, Ngnie-Teta., I, Ag Ag Ayoya., M, Khan.,M,Striley., C. W, Boldon., E.., Clermont., M. (2015). Determinants of Institutional Delivery Among Women of Childbearing Age in Rural Haiti.

UN. (2015). The Millennium Development Goals Report 2015. (15-04513). New York: UNITED NATIONS Retrieved from http://mdgs.un.org., www.un.org/millenniumgoals., www.endpoverty2015.org.

USAID. (2008, 2014). USAID/HAITI COUNTRY PROFILE. Retrieved 8/04/2015, 2009, from retrieved http://www.usaid.gov

WHO. (2015a). Country Profile. Retrieved 4/11/16, 2016, from http//:www.who.int/countries/hti.en

WHO. (2015b). Family Planning / Contraception fact sheets. [http://www.who.int/mediacentre/factsheets/fs351/en/]. (351), 1-4.

WHO. (2016). Maternal Health. World Health Organization 


\section{Appendix A}

Map of Location of Erline et Armelle Clinic in Beaulieu, Haiti

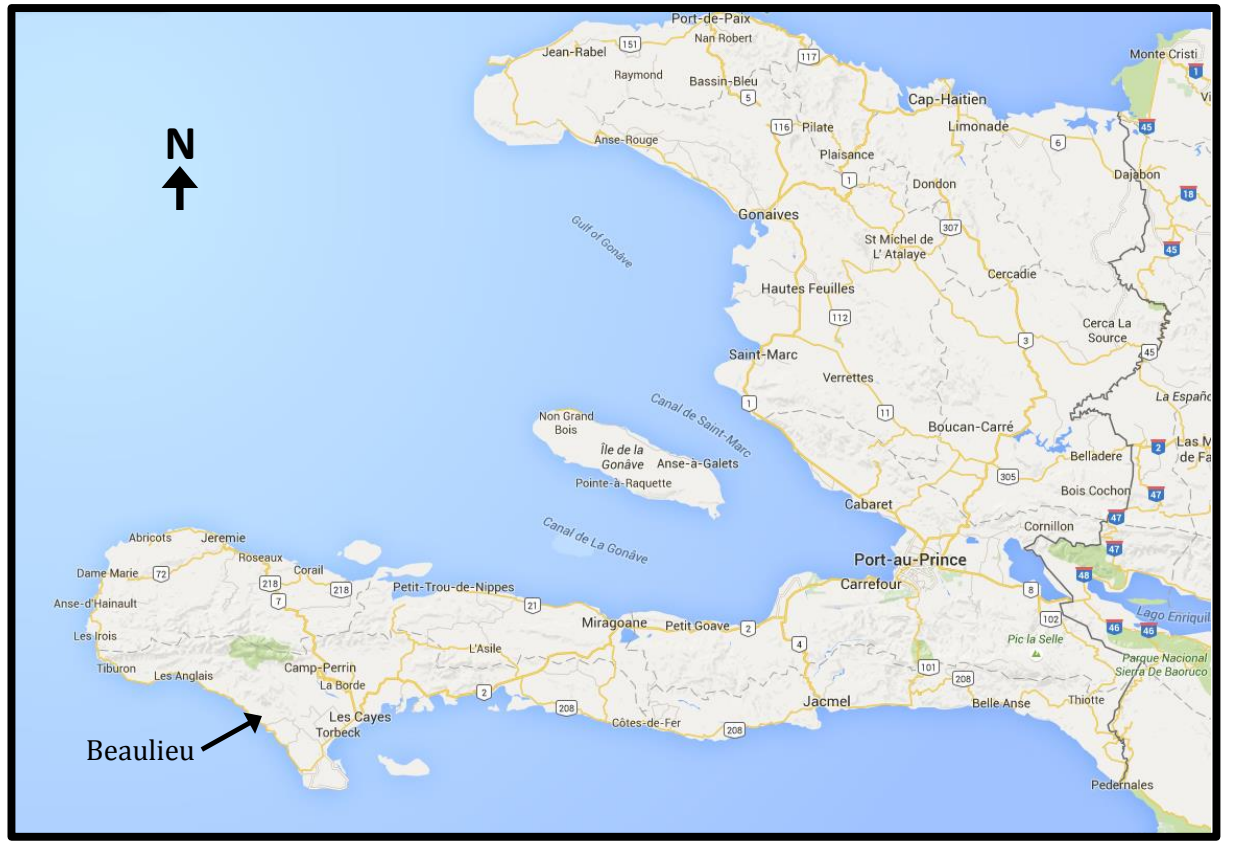

Figure 4. Map of Haiti with location of the Beaulieu Clinic

University of Texas (1999). (Image retrieved from http://www.lib.utexas.edu/maps

/americas/haiti_pol99.jpg) 


\section{Appendix B}

Letter of Agreement Haitian Humanitarian Network

\section{7 (tN) \\ Humanitarian} Network

Institutional Review Board

Rhode Island College

600 Mount Pleasant Avenue

Providence, RI 02908

July 18, 2016

Dear Institutional Review Board:

This letter is provided as agreement that the Board of Directors of the Haitian Humanitarian Network (HHN) approves and will support graduate student Jocelyne De Gouvenain's Masters project that will be conducted at the Erline \& Armelle Clinic in Beaulieu, Haiti.

HHN funds and oversees the Erline \& Armelle Clinic and also serves as a collaborating agency for Rhode Island College School of Nursing graduate student Jocelyne De Gouvenain's Master's Project, Perceived Barriers to Contraceptive Use: An Exploratory Study of Women Living in Rural Haiti.

Following approval by the Rhode Island College Institutional Review Board, the student will be supported to conduct the pilot study at the Erline \& Armelle Clinic between December 2016 and January of 2017 . The Board is completely supportive of the graduate student conducting interviews at the clinic to explore barriers for women who became pregnant while receiving contraceptives.

The purpose of this study is to assess women's perceptions of their health, including barriers to contraceptive use and factors leading to unintended pregnancies. This project is consistent with and supports the HHN mission of promoting optimal health for women and children living in Beaulieu, Haiti, and the surrounding villages.

The HHN Board understands that the study participants will be women of ages 15-55 years living in Beaulieu and surrounding villages that are married or in-union, having 
children and/or pregnant, receiving health care services at the clinic and experiencing unintended pregnancy while receiving contraceptives.

The Board understands that, according to ethical standards for research, informed consent will be obtained verbally using an informational letter explaining the purpose and process of the study, which will be read carefully to the participant in Creole prior to the interview. HHN approves the use of private space in the Erline \& Armelle Clinic for the interviews.

In addition, we understand that the data collection method will involve semi-structured, indepth interviews of approximately 30-60 minutes following consent; that interviews will be audiotaped and transcribed for analysis; and that participants will be given a small gift (health-oriented basket of materials) as a token of appreciation for their time.

The Board understands and agrees that the Erline \& Armelle Clinic patient's participation or lack of participation in the study will not affect their treatment at the clinic nor anyone in their family's treatment at the clinic.

$\mathrm{HHN}$ agrees that and will collaborate to assure that all data obtained will be for research purposes only, will not become part of the participant's medical record, and all results will be de-identified of personal information (name and address) in any research papers and presentations.

The HHN Board looks forward to this collaboration and is grateful to participate in this research with the goal of empowering these women to attain optimal health and prevent further unintended pregnancies.

Sincerely,

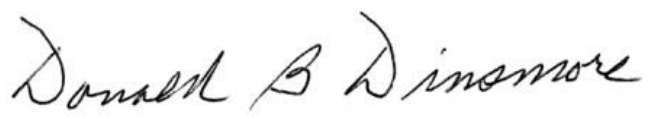

Donald B. Dinsmore

Chairperson, Haitian Humanitarian Network, Inc.

Haitian Humanitarian Network Inc.

64 Hendee Road

Andover, CT 06232 
Appendix C

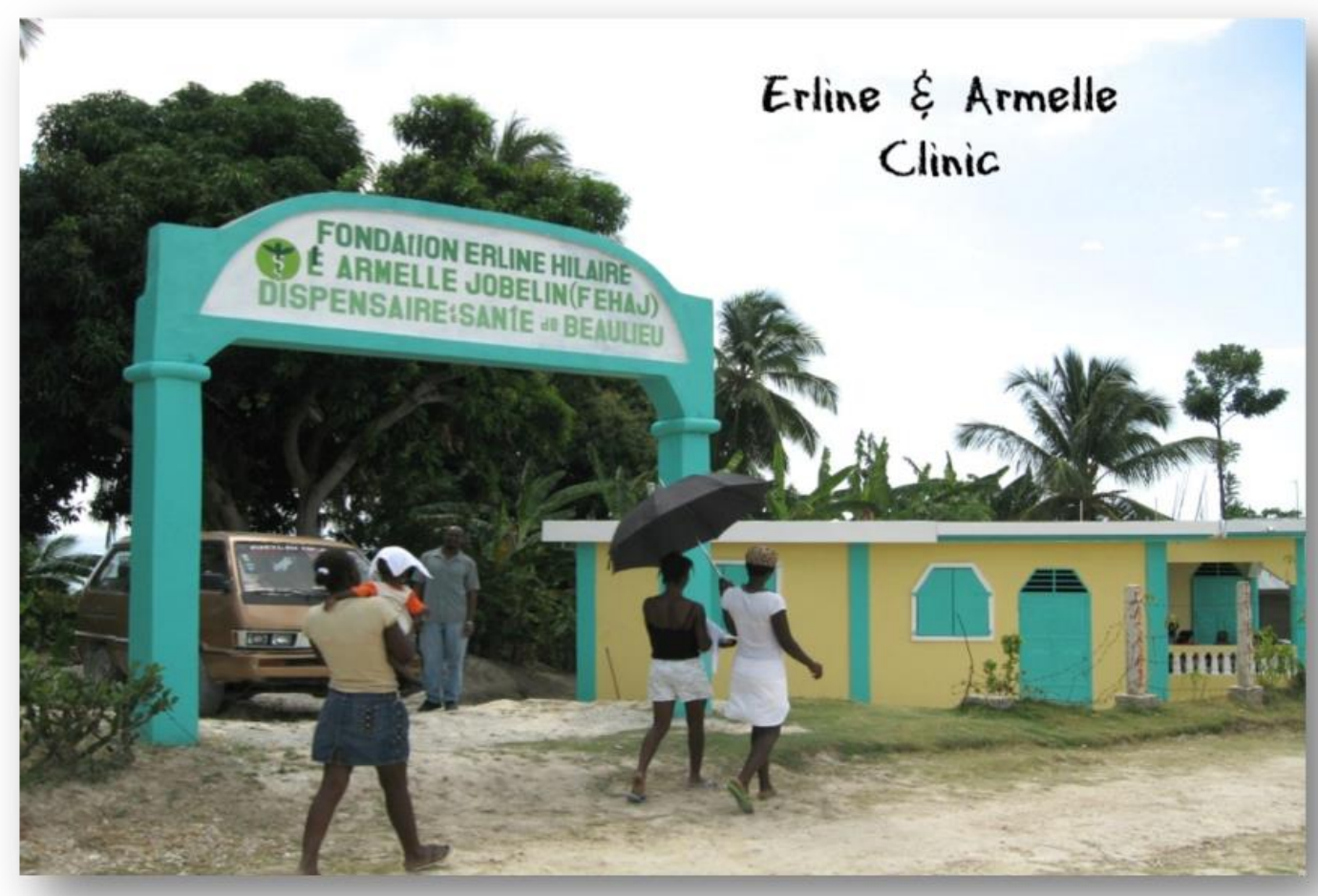




\section{Appendix D}

Script for Clinic Nurse to Invite Participants in English

Erline et Armelle Clinic

Beaulieu, Haiti

English Version:

The Beaulieu Clinic's administration is looking for women who willing to participate in a study that. The opportunity is offered to women in Beaulieu and the surrounding villages. Women are not getting any money to participate. Women's decision to participate or not to participate is volunteer. A student will conduct the study by talking to women who became pregnant while on contraceptives and were not planned to get pregnant. Your experience as women could help us find ways to help women avoid getting pregnant when they do not want too. You do not have to participate, and if you do not want too, your decision would not affect the care that you and your family receive at the clinic. 


\section{Appendix E}

Script for Clinic Nurse to Invite Participants in Haitian Creole

Erline et Armelle Clinic

Beaulieu, Haiti

Klinik Beaulieu a ap chache fam pou paticipe nan you etide. You etudyant ki ta rinmanin pake ak fam ki vine ansent pendan yap pran medikaman planning familial la a. Klinik la a pap payè moune pou patisipe nann etide la a. Esperience ou ta ka ede nou konpran pou kisa you fam ki ap ran planning tombe ansent. Konsa nou ta capab ede pou emepeche sa rive. Nou ta konta si ou ta patisipe min se you bagay volonte. Si ou deside pa patisipe sa pap derange syon ou ak famil ou kon jouin na klonik la a.

Translated from English to Haitian Creole by Jocelyne de Gouvenain

Revised by Roland de Gouvenain 


\author{
Appendix F \\ Informational Letter in English \\ CONSENT DOCUMENT \\ Rhode Island College
}

\title{
ASSESSMENT MATERNAL HEALTH IN RURAL HAITI
}

You are being asked to participate in a study to assess maternal health in rural Haiti, Beaulieu and other villages. You are being asked because you are women who is getting heath care and planning familial at the Beaulieu Clinic, and your experience as women living in Beaulieu and other villages who become pregnant when you do not want too may provide good information on what it feels to deal with pregnancy when do not want to be pregnant. In addition, as women who become pregnant while getting family planning you could helpful in finding out the reasons why women become pregnant when they are getting medications to prevent it. As Participants you could do that by sharing your own experience with the student. Participants would be childbearing women aged 18-55. The form content will be read to participants by student in Haitian Creole using words that are familial to the villagers.

Jocelyne de Gouvenain, BSN, RN, a student in the Master's program at Rhode Island College, is doing this study. Professor Joanne Costello is the faculty advisor

\section{Why this Study is being Done (Purpose)}

I am doing this study to assess women's perception of their health, including barriers to family planning and reasons why women become pregnant while getting planning familial medications and do not want to be pregnant in selected sample of women of childbearing age living in Beaulieu, Haiti and other villages.

\section{What You Will Have to Do (Procedures)}

If you choose to be in the study, we will ask you to:

- To be interviewed with yes or no questions developed by student who is doing the study and a native Haitian and has lived in Beaulieu. The questions will be based on her knowledge of the Haitian community, cultures and the work that others had done on family planning in Haiti.

- Four to six women will be talked too for approximately 30-60 minutes. The talk will be audiotaped and transcribed for analysis. Talks will take place in a private room at clinic in Beaulieu where women usually get their family planning care. 
- Informed consent will be obtained verbally using an informational letter explaining the reason and process of the study, which will be read carefully to each participant in Haitian Creole prior to the talk.

- The guide for the questions will be written in English and translated into Haitian Creole. The student will talk to each participant separately in Haitian Creole.

- Additionally, participants will be asked about the following information:

- Age

- Marital status

- Education and occupation

- Financial status

- Household composition

- Food security

- Access to potable water and sanitation

- Distance/time to travel to the clinic

\section{You Will Be Paid (Compensation)}

To thank you for your time and effort in participating in the study, you will be given a small gift basket which contains: fabric, a bar of soap; and a hand towel. You may keep the gift basket if you decide to stop your participation. No money will be given.

\section{Risks or Discomforts}

This interview will ask that you talk about pregnancies which you did not want. This could make you upset and bring back bad memories. If you need to speak to someone because you become upset, the clinic nurse will be here to talk with you. You may decide to not answer any questions that make you feel uncomfortable, and you can stop the interview at any time with no problems for you or your family. Your decision not to participate in the study will not affect the care that you and your family gets at the clinic.

\section{Benefits of Being in the Study}

Being in this study could benefit you, other women, and communities and may be the country. Your experiences could help find out the reasons why women become pregnant when they do not want too and developing ways to help them not to become pregnant when they do not want too which may improve your health and the health of your family. There is direct benefit to the student who is doing the study

\section{Deciding Whether to Be in the Study}


Being in the study is voluntary. Women who are asked to participate can decide to do it or to refuse. If you refuse to participate in the study that would affect the care that you or your family gets at the Beaulieu's Clinic. Participants can stop their participations at any time.

\section{How Your Information will be Protected}

Interview data would be collected without key identifier. The results would be summarized across participants and shared in report that would be translated from Haitian Creole to English. Each woman would be interviewed individually in a room with the door close. The student would be the only doing interviews and audiotape participants' information. The audiotape will be kept in a locked suitcase. The information will be kept for a minimum of three years after the study is over, after which it will be destroyed.

\section{Who to Contact}

Participants would be encouraged to ask questions after interview is done, come to the clinic or contact the clinic at 37039531 from 8Am to 4Pm Monday to Friday. Participants could also talk to student while she is there because email is not an option in this particular setting.

If participants have concern and would like to talk to someone other than the student, the clinic nurse will be available as support system because she is the one who runs the family planning program and monitor these women. Participants would be allow to talk to the clinic's nurse in a separate room where they can feel at ease

\section{Statement of Consent}

I have heard and understand the information has been read to me. I am deciding to be in the study "Assessment of Maternal Health in Rural Haiti " I understand that agreeing to participate and that meaning my consent. I can change my mind and quit at any time, and I don't have to give a reason. I am a woman between 18-55 years of age and agreed for my statement and voice to be audiotape recorded and the data would be use for analysis and potentially published in professional journals.

I ___agree __ do not agree to be interviewed and audiotaped recorded for this study. 
Thank you for your participation,

Print Name of Participant:

Signature of Participant:

Date:

Name of Researcher Obtaining Consent: Jocelyne de Gouvenain

$7 / 29 / 2016$ 


\title{
Appendix G
}

Informational Letter in Haitian Creole

\author{
Attestasyon de konsentema \\ College de Rhode Island
}

\begin{abstract}
You lettre pou infome moune ki vle patisipe yo
Barrie nan fe planning familial la a:

You etide pou fam ki ap vive nan zone rural en Haiti
\end{abstract}

Nou mande ou pou patisipe nan etide sa a paske ou se youn nan fam ki resewa planning familial nan klinik Beaulieu a, e ou te vine ansent pendan ou te sou planning la a ki te doué empeché ou vin ansent. Eksperiens sa a ta ka édé klinik la a konprann kijan pou édé fam yo pou yo pa vini ansent pendan yo sou planning la a. Patisipasyon ka édé moun nan klinik la a ak etidyan konpran situasyon ki rend fam yo vini ansent lè yap pran planning la a. Eske sa pap dérangé pou ou ta patagé ak nou kisa ou pensé ki rive. Etide sa a sé pou fam ki age dé 18 à 55 ané selman. Infomasyon ki ékri sou form sa a koté ou ba nou permission pou palé ak ou, ak pou tépé voua ou, etidyan ap li 1 pou ou en Creole Haitien pou ou ka konprann kisa ki ap passé.

Jocelyne de Gouvenain, BSN, RN, se yon etidyan nan program metrize nan College Rhode Island la a. Dr. Joanne Costello se professe konseille li

\section{Pou kisa yap fè etide sa a}

Map fe étude sa a pou cheché konnen kisa ki fè fam yo vini ansent mèm le yo ap prann medikaman planning la a ki ta doué empeché yo vini ansent

\section{Kisa ou dwè fè kom marche a suivre}


Si ou vle patisipe nan etide sa a nap mande pou ou:

1. Ou ap besyen reponde ket oui ou non ketsyon kè etidyan pral mande ou de esperyance. Se etidyan ki develop ketsyon sa yo. Li se yon Ayisyenn ki te fèt ak vive nan Beaulieu

- Se etidyan ki prepare ketsyon say o baze sou konnaisence li de culture Ayisyenn ak lot etide.

- Etidyan ap choizi 4 a 6 fam ki volontè pou patisipe nan you ti koze ou interview, ki ap dure environ 30-60 minites konsa a.

- Etidyan ap tapé voua fam ki patisipe nan kozé ou interview a, lap traduit yo en Englais pou li ka analyzé yo.

- Koze a ou interview ap fèt nan klinik Beaulieu a koté fam yo kon resevoua planning familial la

- Consent ou permisyon ap fèt pa bouch ou a loral, nap sevi bagay ki relé let informel, konsa etidyan ap besyen li lèt sa a en Creole Ayisenn pou chak patisipan avan yo kommace pale pou yo capab konpran avan yo deside pou patisipe.

- Guide pou kozé a ou interview a ap ékri en Englais e tradui en Creole Ayisyenn

- Etidyan ap fe chak koze ou interview apa en Creole Ayisenn.

- Nou pral ramace kit infomasyon sou demographi:

- Age ou lage

- Ou marye, place, fam kay

- Ou te al lékol, nan ki klas ou te rive, ki travay ou kon fè

- Ou ap travay ou non

- Konbyen moun ki nan kay la a

- Kijan zafè mange a ye, ou gin jadin oubyin ou achete mange

- Nou gin dlo potable, nou gin latrine

- Ki distance ou abite ak klinik, konbyin tan li pran ou pou mache de lakay ou a klinik la a

- Ki koté ou habité apré cyclone Matthiew a

\section{$\underline{\text { Ou ap jouin you rekonpense pou patisipasyon ou }}$}

Pou di ou mesi pou tan ou pasé pou fè ti kozé sa a ak pou patisipé nan etide la a, etidyan ap bay ou yon ti panié kado ki pa gwo: yon ti twal, yon ba savon ak yon ti sevièt. Ou ka kenbé ti kado yo si ou desidé ou pa pral patisipé nan etide la anko. Nou pap payé moun lajan pou patisipé nan etide la a.

\section{$\underline{\text { Risk ke ou app ran lè ou deside patisipe nan etude sa a }}$}

Nan ti kozé a etidyan pral palé ak ou de kijan ou te vini ansent san ou pat vlé. Pou kek fam, so ka fè ou vini triste ampil, bay yo ampil remo nan key yo. Pendan nap pale a si ou 
zanti ou vini pa alèz, ou ta vle kriyé, ou pa ka kimbé anko, miss Aime ap la pou édé ou, pou palé ak ou. Ou pa obligé repond yon ketsyon ki fè ou mal, oubyen ki fè ou pa alèz, ou ka kampe koze a ninpot lè ou vle, sa pap yon problem pou ou ni pou famil ou. Si ou deside pou ou pa patisipé pa nan etide la a, sa pa pap dérangé anyen nan syon ou jouin na klinik la a.

\section{$\underline{\text { Ki benefice ou ap jouin le ou patisipe nan etide la a }}$}

Moun ki deside patisipe pap joun yon benefice directemen ou resevoua lajan pou sa a.

\section{$\underline{\text { Dside si ou ta remmen patisipe nan etide la a }}$}

Se ou min sel ki gin dwa deside si ou ta doué patisipé nan etide sa a ou non. Fam ke etidyan ap mandé pou patisipé nan etide la a gin dwa pou patisipé ou non. Si you fam deside pou pa patisipe nan etide la a sa pap changé anyen nan syon li kon pran nan klinik la a. Fam ki deside patisipe nan etide la gin dwa pou kampé patisipasyon yo ninpot ki le.

\section{Kijan ou pral protégé infomasyon yo}

Etidyan a ap ramacé infomasyon yon jan ki pap facil pou lot moun konprann ki moun kit e repond yon kestsyon. Chak fam ak gin you numero é se selman etidyan ki ap konnin numero sa yo. Etidyan ap pale ak chak patisipan apa en prive nan yon chambe konsultasyon. Kaset la ki tépé koze entre ou ak etidyan ak patisipan an pral rete anba klè pendan au mouin 3 an aprè sa nou pral krazè li pou moun pa jouin infomasyon an.

\section{$\underline{\text { Ki moun pou kontacte }}$}

Patisipan ka mande ninpot ketsyon kè yo vlè kounyè a. Si ou gin you ketsyon pi ta, ou ka rélé klinik la a nan nimero 37039531 de 8 è di matin a 4 è apre midi depi Lundi rivè Vendredi pouk a palè ak Miss Aimè. Ou ka mandè li pouk a palè ak Jocelyne de Gouvenain at 401-248-5435 or jdegouvenain@yahoo.com. Ou ka palè ak konseillè etidyan an Dr. Joanne Costello a 401-451-6559 or jcostello@ ric.edu. 


\section{Propo Dako ou konsentmen}

Mouin tandé é konpran infomasyon ke yo li bam lan lan. Mouin choisi pou pran pa nan etide sa a. " "Evaluasyon Zante Manman nan Rural Haiti”. Mouin komprann sa vle di mouin dako e moun bay knosentman m pou m patisipé nan etide la a. Mouin ka deside kité etide la a, a ninpot kile sans mouin pa obligé bay you rézon. Mouin sé you fam entre 18 a 55 an age e mouin dako pou voua mouin enregistre sou you tépé a kaset é infomasyon sa o pral sevi pou analyzé è min pibliyé nan you journal professional.

Mouin __ dako __ mouin pa dako pou voua mouin tépé ou enregistre nan you kaset pou etide sa.

Non/prenom:

Signature: Date:

Nom etidyan ki ap fè recherche la a: Jocelyne de Gouvenain $7 / 29 / 2016$

Translated from English to Haitian Creole by Jocelyne de Gouvenain

Revised by Roland de Gouvenain 


\section{Appendix $\mathbf{H}$}

\section{Interview Guide for Master's Project Jocelyne DeGouvenain: English}

1. How old are you?

2. How many times you got pregnant in your life? How old were you when you got pregnant the first time? How many time you delivered a child alive? How many children do you have? How old are they?

3. Have you ever been to school? For how long? Do you know how to read or write?

4. Do you thing religion has anything to do with you making decision about family planning? May you we talk more about it?

5. I know you come to the clinic often to get medication for family planning because you want like decide when to get pregnant? May you talk to me little bite about that? What medications have you taken? How long have you been taking family planning medications? Do you have any problem with the medication?

6. May you tell me why you made the decision to do family planning? How do you thing having a lot of children affect you, your children and family? May you talk about how you think family planning can help you, your children and family with a better health and better future?

7. You and I talked about you got pregnant when you were getting medication to avoid getting pregnant? Can you tell anything about the time when you got pregnant while you were taking the medication? How many time? What do you think happened you got pregnant while on the medication? May be you and I can try to understand what happened that can be useful to you and other women?

8. How do you think the medication works to help women from getting pregnant? May you tell me in your own words how the medication works?

9. The medication works to prevent pregnancy if you take it at the same every day. May talk to me about how the medication works for you? Do you take the medication at the same time every day? How do you usually take your medication? Do you have any difficulty in your way of taking the medication at the same time every day?

10. How you usually get your medication. Do you come to the clinic every month to get your pills or every three months for your injection? How is this for you? Is it hard for you to get to the clinic? How long you have to work to get to the clinic? Is it hard to get to the clinic? How much you have to pay to get to the clinic? How to you get to the clinic (walk, donkey, horses, mules, motorcycles etc)? How often you have problem getting to the clinic and not able to get your medication on time? What do you think the clinic could do to make easier for you and other women?

11. The medication works to prevent women from getting pregnant when they take it at the same time every day. May you tell me how this works for you? Do you take 
your medication at the same time every day? Is there anything in the way of you taking your medication at the same time every day?

12. Do you have a husband or in-union partner? Does your husband or partner know that you are taking family planning medications? Does your husband or partner support your taking the medication? Do you have to hide your medication from your husband or partner? Is this cause problem for you?

13. Do you have your own house? Was your house destroyed during hurricane Matthew? Where you and your family live now? Where does the family spend the day? Where does the family spend the night? Do you live with your in-laws? Does living with your in-laws influence your taking your family planning medication? Do you hide that you take medication to avoid getting pregnant from your in-laws? How is it for you and the family?

14. Because of the hurricane life is very difficult? How do plan on taking your medication? Would that be helpful if the clinic make special arrangement during this difficult time?

15. Hurricane Matthew is very hard on you, your family and the village? The interviewer will stop the interview and talk about the hurricane whenever you want because she knows that it very important that you talk to someone about that experience as is it part of your life now?

16. Do you work outside the home? What do you do for living? Does your work causes problem for to get your family planning medication every month or every three months? Anything that the clinic could do to make it easier for you to get your medication while you are working.

17. I would like to talk to you about any other problem that might be in the way of you taking your family planning medication.

18. I would like to know about anything that you think can help you or other women from getting pregnant when they do not want too. Please let me know if you have any idea on how the clinic can better help. 


\section{Appendix I}

\section{Interview Guide in Haitian Creole}

1. Ki laj ou?

2. Konbyen fwa ou te ansent nan lan vi ou? Ki laj ou te genyen le ou te ansent premye fwa? Konbyen pitit vivan ou te akouche? Konbyen pitit ou genyen kounye a? Ki laj pitit ou yo?

3. Ou te al lekol wi / non, si wi pendan konbyen ane? Eske ou konn li ak ekri?

4. Si sa a pap derange ou, eske ou panse relijyon afekte desizyon pa ou pou fè planning familial?

5. Mwen konprann ou nan pwogram planning familial nan klinik la a, epi malgre sa ou te vin ansent kant meme. Eske sa pap derange ou si mwen fè you ti pale avek ou sou sa a? Ki kalite medikaman ou konn pran? Depi konbyen tan ou te sou metod planning lan? ki difikilte ou jwenn ak planning la a?

6. Mouin ta renmen mande ou poukisa a ou pran desizyon pou fè planning? Eske ou panse fe mwens pitit t'ap pi bon pou ou, pou lot pitit ou yo ak pou fanmi la? Tanpri souple di mwen kijan ou panse planning la a t'ap ede ou, ede pitit ou ak ede famil ou pou nou ta genyen pi bon lasante?

7. Nou te pale sou zafe ou te vin ansent pendan ke ou t'ap prann medikaman pou ou pa vine ansent? Eske ou ka dime konbyen fwa ou fè pitit pendan oy t'ap prann medikaman sa yo ? Kijan ou panse ou te vine ancent malgre ou t'ap prann medikaman sa yo ? Infomasyon sa a t'ap bon pou nou ka ede ou ak lot fam ki pa vine ancent.

8. Mwen ta renmen pale ak ou sou kijan ou konprann metod planning ap travay pou anpeche fanm yo vin ansent. Sa pap deranje ou si ou dim kisa ou panse de sa a ? Eske gen

you infomasyon ki te ka ede ou konprann pi byen kijan planning la ap travay nan ko moun?

9. Medikaman planning lan anpeche ou vin ansent si ou pran li menm le a chak jou. Eske ou ka prann medikaman sa a chak jou a menm le a ? Eske ou ka dim ki problem ki anpeche ou pran medikaman an a menm le a chak jou ? Sa pap deranjew si ou explike m kisa ou fè, ki metod ou utilize pou prann medikaman sa a chak jou ? Eske gen you bagay ki anpeche ou suiv routine la a? (Kijan ou fè pou ou ka sonje prann medikaman sa a chak jou).

10. Kijan ou fè pou jwenn medikaman an? Eske ou vin nan klinik la chak mwa pou prann pillul, grenn ou konprime? Oubyen ou pran you injecsyon, piki chak 3 mwa ? Kijan sa a mache pou ou ? Eske ou gen problem pou vin nan klinik la ? Ki distans ou mache pou vin nan klinik la a ? Pa ki mwayen ou vin nan klinik la, mache, sou bourik, milet, moto, oswa machine ? Konbyen li koute pou ou vin nan klinik la a ? Konben fwa ou pat te kapab vin nan klinik la a e donk ou pa ta kapab prann medikaman yo le ou te dwe prann yo ? Eske ou ka partaje sitiasyon sa a ak mwen, eske ou genyen yon ide de kisa ou ka fe pou fè bagay la pi fasil pou ou?

11. Medikaman planning lan se you bagay ou bezwen prann chak jou a menm le.? Eske ou pran medikaman chak jou a menm le a ? Si ou pa pran li a menm le chak jou, kisa ki empeche ou? 
12. Ou marye oubyen ou plase? Eske mari ou ou gason ou konnen ou fè planning ? Eske li dako pou ou prann medikaman planning ? Sowa ou kache sa a pou li pa konnen sa a ? Eske sa a difisil pou ou?

13. Eske ou habite nan kay pa ou ? Eske ou habite ak fanmi mari ou oswa gason ou ? Eske se you problem pou ou pou fè planning la a ? Eske ou kache zafe planning nan de famil mari ou ou gason ou ? Eske sa difisil pou ou?

14. Eske ou kon al nan travay en deyo kay la a ? Ki kalite travay ou kon fè? Eske travay la a anpeche ou pran medikaman jan ou ta doue pran li chak jou ou chak 3 mwa? Souple di mwen kisa klinik la a ka fè pou ou, pou ou ka jwenn medikaman menm le ou bezwen travay?

15. Ki kalite lot bagay ap anpeche ou pran medikaman planning la a ?.

16. Eske ou ka di mwen kisa ou panse ki ka anpeche ou ak lot fam yo vin ansent pandan yap prann medikaman planning la a ? Si ou gen you ide sou kisa klinik la ta dwe fe pou ede nou, souple partage li ak mwen.

Translated by Jocelyne de Gouvenain, BSN, RN Date : 9/24/2016

Verified/revised by Roland de Gouvenain, PhD Date : 9/24/2016 


\section{Appendix J}
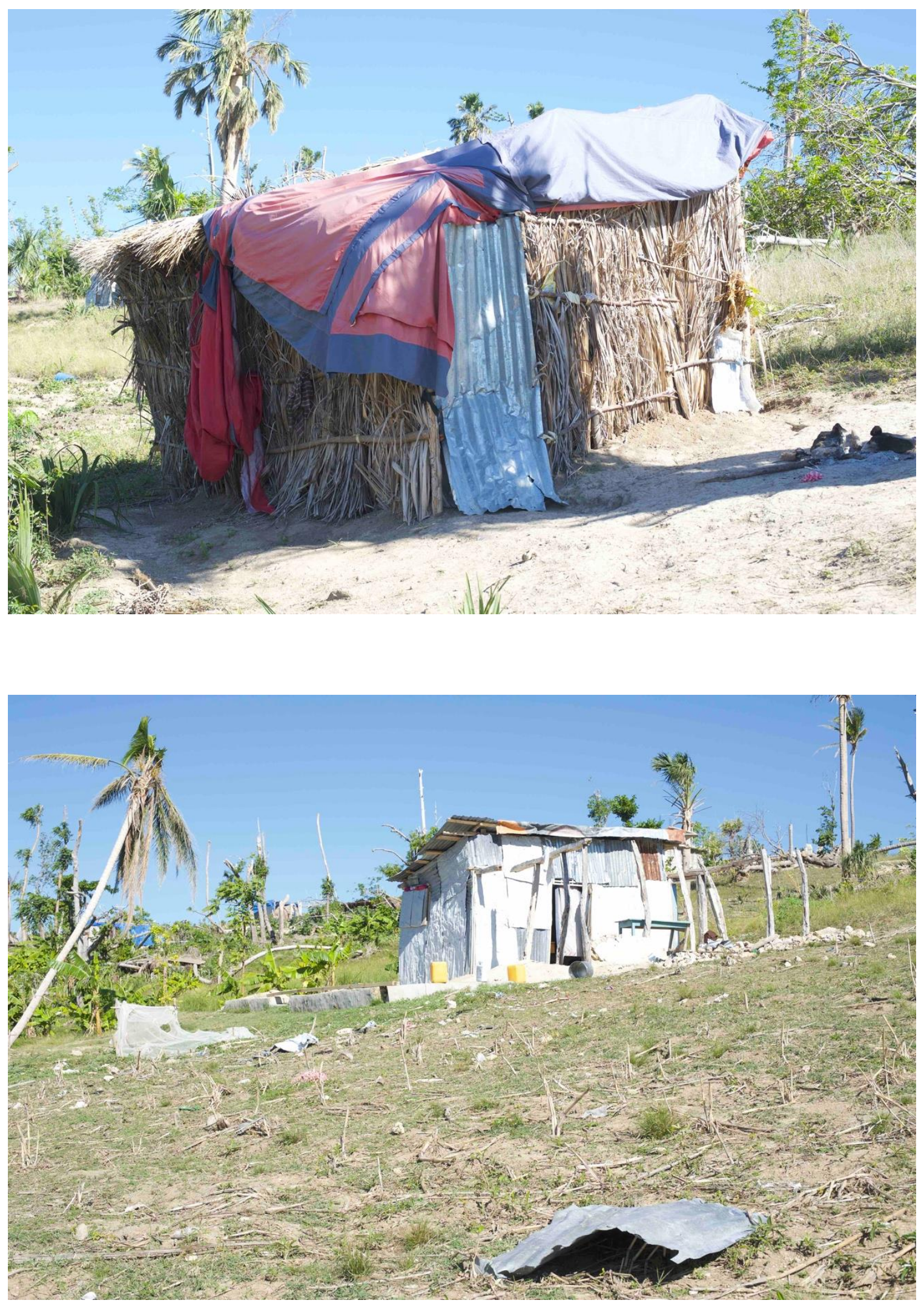